\title{
The analysis of leakage condition for heating network
}

\author{
Yuanxiong $\mathrm{Fu}^{1}$, a , Lijun $\mathrm{Zhao}^{2}$ and Chao $\mathrm{Han}^{3}$ \\ ${ }^{1}$ Beijing Jingneng Future Gas-fired Thermal Power Co.,Ltd., Beijing,China \\ ${ }^{2}$ Beijing Jingneng Future Gas-fired Thermal Power Co.,Ltd., Beijing,China \\ ${ }^{3}$ Beijing Jingneng Future Gas-fired Thermal Power Co.,Ltd., Beijing,China \\ aemail:asd0110dsa@sina.com
}

\begin{abstract}
Keywords: heating network; graph theory; genetic algorithm; leaky section; hydraulic regime Abstract. When the pipeline bursts and leaks, the make-up pumps will turn on to supple the network with water. Due to the outdoor heating network is a closed cycle, and equipped with the make-up water pumps, the hot water will leak continually under a constant pressure at the leak point, which causes thermal waste. Therefore, locating the leaky section in heating network is more and more important. In this paper, the mathematical model of a branching pipe system was established by using the graph theory and genetic algorithm. Programming calculated the flow and pressure of all pipe sections and heat exchange stations when the network is normal operation and leaky operation, respectively. And through analysis of the change law of pressure and flow, the rules of hydraulic regime changes can be obtained. Moreover, the leaky section will be found out efficiently.
\end{abstract}

\section{Introduction}

With the development of central heating industry, the cover area of city heating network is bigger and bigger, and the corresponding accidents and economic losses caused increasing. Therefore, locating the leaky pipe sections and ensuring the heating pipe network secure operation are becoming more and more urgent.

Graph theory as an extension of the disciplines of mathematics, discusses the correlation between the objects, which communicates with each other in a particular way [1]. With the emergence of high-end computers, the application of graph theory, especially the research methods of mathematical model of the network has been an unprecedented development. Milos Teodor, Alexandrescu Aurora and Dobanda Eugen presented the application of graphs theory for determining the optimal route of a pipeline supply being at the great distance of the target consumer. It applies when the distance from source to target, because the configuration of the land, there are several variants of the route passing through some mandatory points. In this way the route has $\mathrm{n}$ sections and on each section the total cost has a certain value [2]. Ji Shi and Fengzhou Zhang used graph theory to the design of water supply pipeline and the accessories of system were taken into calculation [3], so the result would be more accurate. Sujuan Zheng and Xiaolin Xu applied the graph theory in decision making information system for urgent repair of urban water supply piping network, and proposed an effective scheme of valve shutdown [4].

Genetic algorithm is applied to solute the optimization problem.For pipeline optimization problem, M.H. Afshar applied standard binary coded genetic algorithms for the solution of problems with continuous design variables requires discretization of the continuous decision variables. The method was applied to a benchmark problem of a storm water network design, and the results were compared with those of the existing method [6].

In this paper, the heating network model is constructed by using graph theory, and improved genetic algorithm is applied to modify the model. The flow and pressure of each pipe sections and nodes are calculated when the different nodes leak, under the conditions of accident leakage rate less than the maximum supply water quantity of system. Through induction these data, the law of hydraulic regime changes of different pipe leakage can be obtained, and the leaky pipe section can be picked out. 


\section{The graph theory model and genetic algorithm modified model of heating network}

The heating network model based on graph theory.

The formulas of pipe network hydraulic model are shown as follows:

$$
\left\{\begin{array}{l}
A G=Q \\
B_{f} \Delta H=0 \\
\Delta H=S|G| G+Z-D H
\end{array} .\right.
$$

Where, $A$ is incidence matrix defined in graph theory, $G$ is the vector of flow in network's branches $(\mathrm{t} / \mathrm{h}), Q$ is the vector of inlet flow in network's nodes $(\mathrm{t} / \mathrm{h}), B_{f}$ is the matrix of the fundamental circuit, $\Delta H$ is the vector of drop of pressure head in network's branches (Pa), $S$ is the diagonal matrix of the resistance characteristic coefficient $\left(\mathrm{Pa} \cdot \mathrm{h}^{2} / \mathrm{t}^{2}\right),|G|$ is the diagonal matrix of absolute value of flow in network's branches $\left(\mathrm{m}^{3} / \mathrm{s}\right), Z$ is the two nodes potential energy difference column vector $(\mathrm{Pa}), \mathrm{DH}$ is the vector of pump lift pressure head in network's branches $(\mathrm{Pa})$.

For heating pipe network, the water flow state is in the square resistance zone. The formula of pipe resistance coefficient is expressed to:

$$
S=6.88 \times 10^{-9} \frac{K^{0.25}}{d^{5.25}}\left(l+l_{d}\right) \rho .
$$

Where, $d$ is the pipe diameter $(\mathrm{m}), l$ is the pipe diameter $(\mathrm{m}), l_{d}$ is the equivalent length of pipe's local resistance $(\mathrm{m}), \rho$ is the density of water $\mathrm{kg} / \mathrm{m}^{3}, K$ is the equivalent absolute roughness of pipe, and the outdoor pipe network is estimated to be $0.5 \mathrm{~mm}$.

\section{The genetic algorithm modified model}

Because the equivalent absolute roughness $\mathrm{K}$ and the equivalent length of pipe's local resistance $l_{d}$ are not precise, the pipe resistance coefficient need modified. In this paper the improved genetic algorithm is applied, the algorithm flowchart is shown in Fig.1.

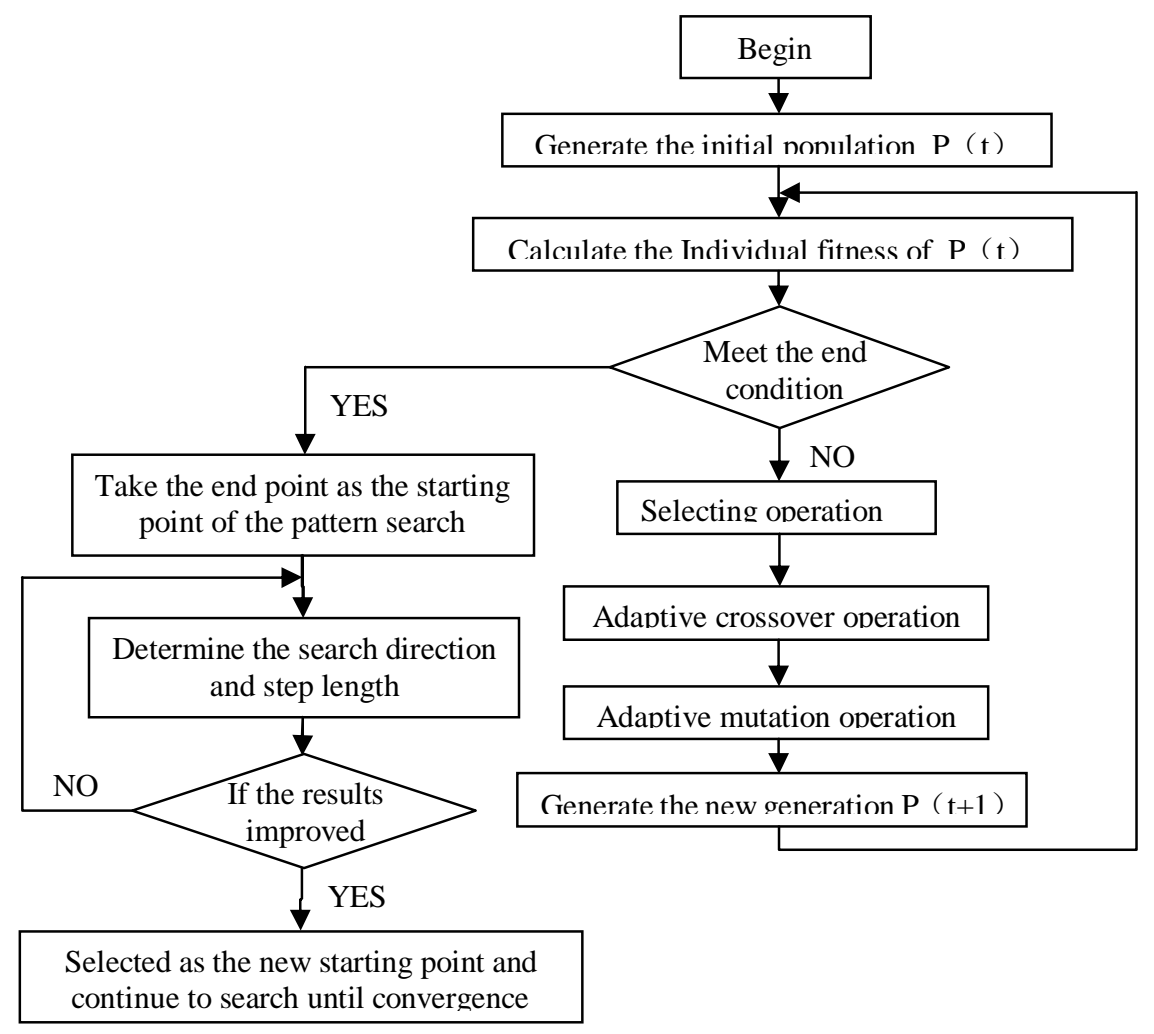

Fig.1 The algorithm flowchart 
The adaptive crossover probability $P_{c}$ and adaptive mutation probability $P_{m}$ are shown as:

$$
\begin{aligned}
& P_{c}= \begin{cases}0.9-\frac{0.3\left(f_{\max }-f^{\prime}\right)}{f_{\max }-f_{\text {avg }}} & f^{\prime} \geq f_{\text {avg }} \\
0.9 & f^{\prime}<f_{\text {avg }}\end{cases} \\
& P_{m}= \begin{cases}0.1-\frac{0.099\left(f_{\max }-f\right)}{f_{\max }-f_{\text {avg }}} & f \geq f_{\text {avg }} \\
0.1 & f<f_{\text {avg }}\end{cases}
\end{aligned}
$$

In this algorithm, the end point of genetic algorithm is taken as the starting point of the pattern search, so the result could be more accurate.

For a heating network, the genetic algorithm modified model is built:

$$
\min F(S)=\sum_{i=1}^{N}\left(P_{i c}-P_{i s}\right)^{2}
$$

constraint condition: $\left\{\begin{array}{l}\sum G_{m, i j}+Q_{i}=0 \quad(i=1,2 \cdots, N) \\ P_{i j}=S_{i j}\left|G_{m, i j}\right| G_{m, i j}-d H_{i j} \quad(i=1,2 \cdots, N) \\ S_{\min } \leq S_{i j} \leq S_{\max } \quad(i=1,2 \cdots, N)\end{array}\right.$.

Where, $P_{i c}$ is the pressure measuring point of heating network, $P_{i s}$ is the pressure calculate point of heating network. $S_{\min }$ is the minimum value of resistance characteristic coefficient, and $S_{\text {man }}$ is the maximum value of resistance characteristic coefficient.

\section{Results and discussion}

The experiment table can be abstracted as follow calculation model,Fig.2.

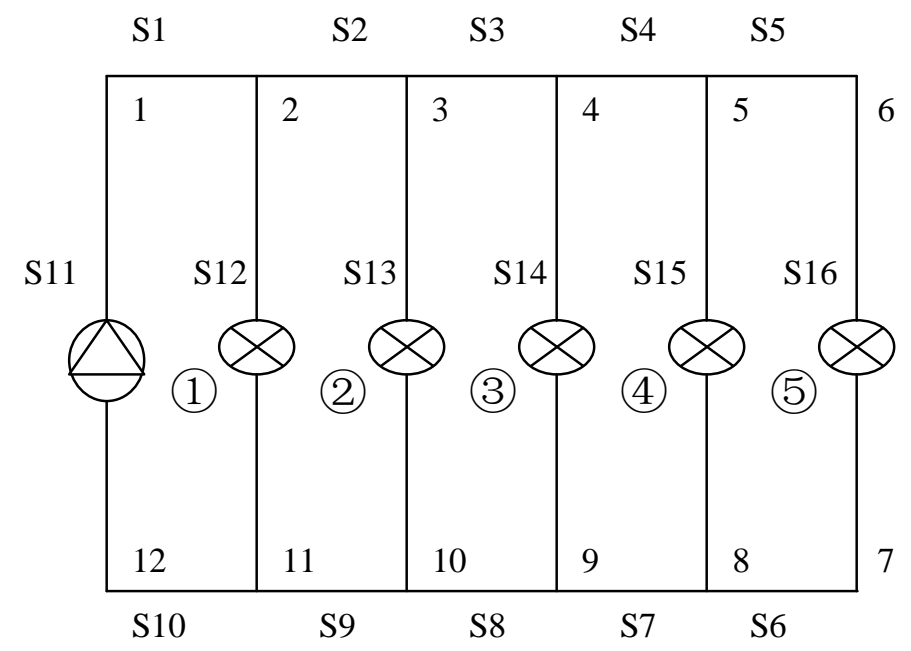

Fig. 2 The calculation model of experiment table

Because of the limited space, the leak point on section S3 was taken as an example. And the node pressure calculated by graph theory and genetic algorithm were compared. Node 12 is the constant pressure point, so it's a constant. 
Table 1 The node pressure when the system was normal operation

\begin{tabular}{cccccc}
\hline $\begin{array}{c}\text { Node } \\
\text { number }\end{array}$ & $\begin{array}{c}\text { Measured } \\
\text { value }(\mathrm{Pa})\end{array}$ & $\begin{array}{c}\text { Result of } \\
\text { graph } \\
\text { theory }(\mathrm{Pa})\end{array}$ & $\begin{array}{c}\text { Error } \\
\text { rate }\end{array}$ & $\begin{array}{c}\text { Result of genetic } \\
\text { algorithm (Pa) }\end{array}$ & $\begin{array}{c}\text { Error } \\
\text { rate }\end{array}$ \\
\hline 1 & 349450 & 344250 & $1.49 \%$ & 347950 & $0.43 \%$ \\
2 & 343024 & 338470 & $1.33 \%$ & 341580 & $0.42 \%$ \\
3 & 333428 & 329570 & $1.16 \%$ & 332450 & $0.29 \%$ \\
4 & 326302 & 323180 & $0.96 \%$ & 325410 & $0.27 \%$ \\
5 & 315718 & 313210 & $0.79 \%$ & 314900 & $0.26 \%$ \\
6 & 305764 & 303590 & $0.71 \%$ & 304970 & $0.26 \%$ \\
7 & 208273 & 206100 & $1.29 \%$ & 207480 & $0.47 \%$ \\
8 & 196769 & 195600 & $0.75 \%$ & 195990 & $0.50 \%$ \\
9 & 186454 & 186250 & $0.14 \%$ & 185830 & $0.43 \%$ \\
10 & 173161 & 173460 & $0.22 \%$ & 172810 & $0.26 \%$ \\
11 & 165250 & 165810 & $0.45 \%$ & 165160 & $0.07 \%$ \\
\hline
\end{tabular}

Table 2 The node pressure when section S3 leak $2 \%$ of total circulation flow

\begin{tabular}{cccccc}
\hline $\begin{array}{c}\text { Node } \\
\text { number }\end{array}$ & $\begin{array}{c}\text { Measured } \\
\text { value(Pa) }\end{array}$ & $\begin{array}{c}\text { Result of } \\
\text { graph } \\
\text { theory(Pa) }\end{array}$ & $\begin{array}{c}\text { Error } \\
\text { rate }\end{array}$ & $\begin{array}{c}\text { Result of genetic } \\
\text { algorithm(Pa) }\end{array}$ & $\begin{array}{c}\text { Error } \\
\text { rate }\end{array}$ \\
\hline 1 & 348451 & 343220 & $1.50 \%$ & 344670 & $1.09 \%$ \\
2 & 342301 & 337270 & $1.47 \%$ & 338540 & $1.10 \%$ \\
3 & 331651 & 327530 & $1.24 \%$ & 327870 & $1.14 \%$ \\
4 & 324414 & 321090 & $1.02 \%$ & 320990 & $1.06 \%$ \\
5 & 313707 & 311390 & $0.74 \%$ & 311300 & $0.77 \%$ \\
6 & 304465 & 302080 & $0.78 \%$ & 302060 & $0.79 \%$ \\
7 & 208057 & 205670 & $1.42 \%$ & 205650 & $1.43 \%$ \\
8 & 196414 & 195500 & $0.58 \%$ & 195010 & $0.90 \%$ \\
9 & 185574 & 186400 & $0.57 \%$ & 184260 & $0.90 \%$ \\
10 & 175059 & 173910 & $0.85 \%$ & 174480 & $0.43 \%$ \\
11 & 165044 & 166370 & $1.06 \%$ & 164910 & $0.11 \%$ \\
\hline
\end{tabular}

Table 3 The node pressure when section S3 leak 5\% of total circulation flow

\begin{tabular}{cccccc}
\hline $\begin{array}{c}\text { Node } \\
\text { number }\end{array}$ & $\begin{array}{c}\text { Measured } \\
\text { value }(\mathrm{Pa})\end{array}$ & $\begin{array}{c}\text { Result of } \\
\text { graph } \\
\text { theory }(\mathrm{Pa})\end{array}$ & $\begin{array}{c}\text { Error } \\
\text { rate }\end{array}$ & $\begin{array}{c}\text { Result of genetic } \\
\text { algorithm }(\mathrm{Pa})\end{array}$ & $\begin{array}{c}\text { Error } \\
\text { rate }\end{array}$ \\
\hline 1 & 343536 & 336770 & $1.97 \%$ & 337560 & $1.74 \%$ \\
2 & 337323 & 330600 & $1.99 \%$ & 331330 & $1.78 \%$ \\
3 & 326661 & 320460 & $1.90 \%$ & 320660 & $1.84 \%$ \\
4 & 318787 & 313980 & $1.51 \%$ & 313410 & $1.69 \%$ \\
5 & 308395 & 304610 & $1.23 \%$ & 305210 & $1.03 \%$ \\
6 & 299128 & 295590 & $1.18 \%$ & 295990 & $1.05 \%$ \\
7 & 205180 & 201640 & $2.14 \%$ & 203050 & $1.29 \%$ \\
8 & 193019 & 191790 & $0.80 \%$ & 189940 & $2.01 \%$ \\
9 & 182357 & 183000 & $0.45 \%$ & 179550 & $1.97 \%$ \\
10 & 172626 & 171020 & $1.21 \%$ & 171250 & $1.04 \%$ \\
11 & 162196 & 163670 & $1.21 \%$ & 161900 & $0.24 \%$ \\
\hline
\end{tabular}




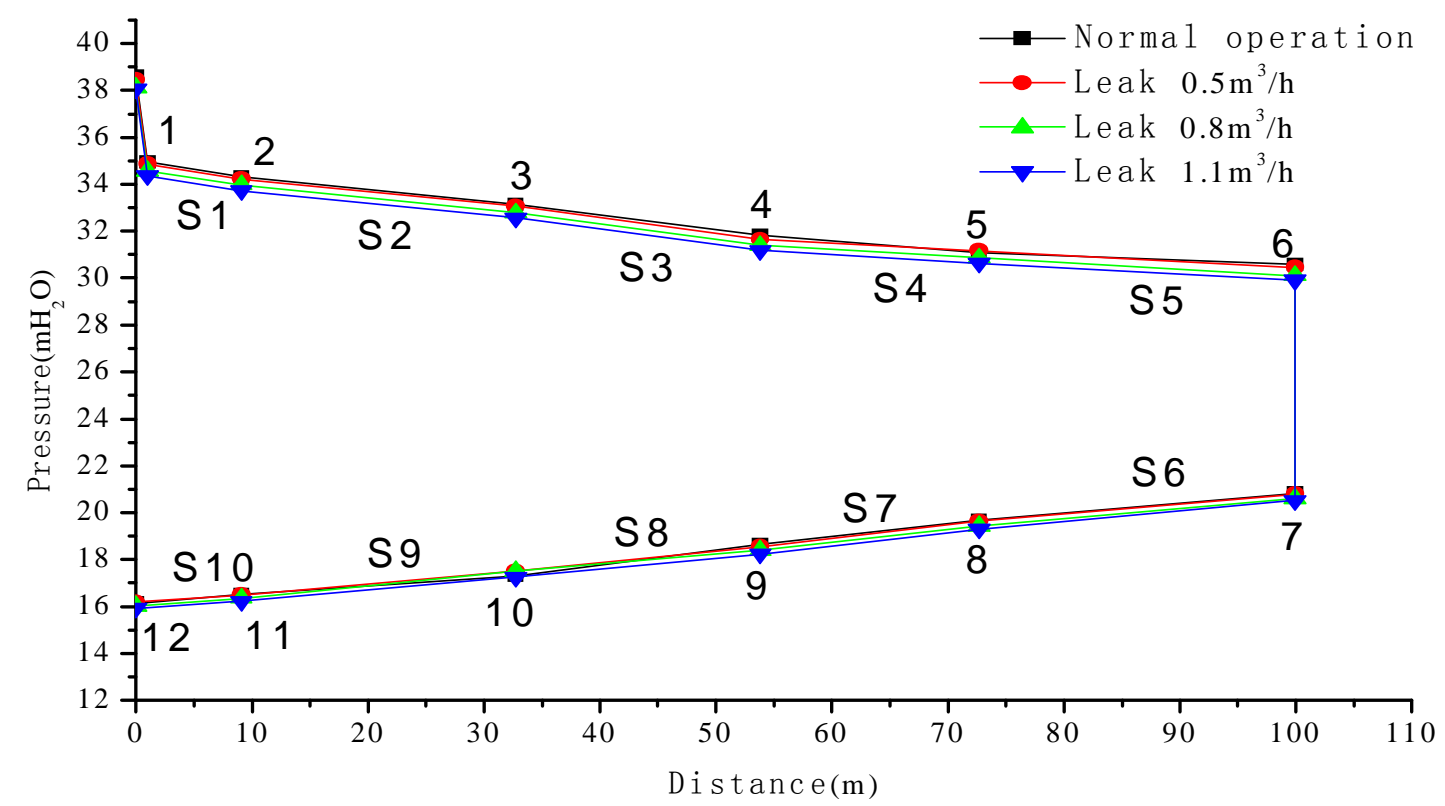

Fig.3 The change of pressure diagram

\section{Conclusions}

From Table 1 to Table 3 and Fig.3, it is concluded that:

1) After apply the genetic algorithm, the calculation accuracy of node pressure improved. Because the resistance coefficient is derive from the experiment table, so the deviation is not big.

2) All nodes pressure decrease, except to the constant pressure point, the pressure of node 4 drops tempestuously when section S3 leaks. The pressure decrease rate between the heat source and node 4 is greater than the decrease rate between node 4 and the end of pipe network. The hydraulic gradient between the heat source and node 4 becomes steeply, and the hydraulic gradient between node 4 and the end of pipe network becomes gently.

3) When the leakage quantity increases, these trends remain unchanged, but the change range increases. When leak occurs on water supply pipe, the change of main pipe flow and pressure diagram is independent on leakage. As long as the water supplied by make-up pump meets the leakage quantity, the change trend of system hydraulic keeps on invariant.

If you follow the "checklist" your paper will conform to the requirements of the publisher and facilitate a problem-free publication process.

\section{Acknowledgements}

This work was supported by the experimental platform of North China Electric Power University.

\section{References}

[1] Graph theory and its applications [M]. Nanjing: Southeast University Press,2002: 1-168. In Chinese.

[2] Milos Teodor; Alexandrescu Aurora and Dobanda Eugen.Optimal routes of pipeline supply from source to consumer objective using graph theory $[\mathrm{M}]$. 20th International Danube-Adria-Association-for-Automation-and-Manufacturing Symposium.vol(20), 631-632, 2009.

[3] Ji Shi and Fengzhou Zhang. Graph theory applied to pipe-network hydraulic analysis [J]. Journal of Hydraulic Engineering, Vol.8 No.2, 1999, 49-56. In Chinese. 
[4] Sujuan Zheng and Xiaoling Xu. Decision making information system for urgent repair of urban water supply piping network based on graph theory[J]. Journal of Hohai University, Vol.29 No.5, 2001, 92-95. In Chinese.

[5] M.H. Afshar. Rebirthing genetic algorithm for storm sewer network design[J]. Scientia Iranica. 2012,19(1):11-19.

[6] Xiangzhao Fu, Qingxi Mao. Fluid Distribution Network, chapter, 8, China Construction industry press (2006) P.282. In Chinese.

[7] Deying Li, Wenfa Xu: Heat Supply Engineering, chapter, 3, China Construction Industry Press(2006), P51. In Chinese. 